\title{
Immunohistochemical localization of epidermal growth factor receptors, epidermal-growth-factor-like and transforming-growth-factor- $\alpha$-like peptides in chicken ovarian follicles
}

\author{
O. M. Onagbesan ${ }^{1}$, W. Gullick ${ }^{2}$ I Woolveridge ${ }^{1}$ and M. J. Peddie ${ }^{1}$ \\ ${ }^{\mathrm{I}}$ Department of Physiology and Pharmacology, Biomedical Sciences Building, University of Southampton, \\ Southampton SO9 3TU, UK, and 'Imperial Cancer Research Fund, Molecular Oncology Unit, \\ Hammersmith Hospital, London W12 ONN, UK
}

\begin{abstract}
The purpose of this study was to determine the presence of epidermal growth factor receptor and its potential ligands epidermal growth factor (EGF) and transforming growth factor $\alpha$ (TGF- $\alpha$ ) in the tissues of the maturing follicles in the ovary of laying ISA-Brown hens using peptide-specific immunohistochemical methods. Cryostat sections, $6-8 \mu \mathrm{m}$ thick, were made from fresh-frozen tissues of F1-F4 (largest to fourth largest) and large white follicles and they were immunostained for epidermal growth factor receptor, epidermal growth factor or transforming growth factor $\alpha$ using specific polyclonal antibodies. The EGF receptor and both ligands were detected in the granulosa, theca interna and theca externa layers of the follicles. The EGF receptor was localized both in the plasma membrane and cytoplasm of all cell types. EGF was predominantly cytosolic, whereas TGF- $\alpha$ was found in the plasma membranes and perinuclear areas of all cell types. The concentration of the receptor and both ligands decreased with follicular maturation. This observation is consistent with our previous observation that the response to EGF and TGF- $\alpha$ decreases as follicles mature, and thus provides further evidence that the receptor or the ligands may have a regulatory role in avian ovarian function.
\end{abstract}

\section{Introduction}

The epidermal growth factor (EGF) family of proteins [EGF, transforming growth factor $\alpha$ (TGF- $\alpha$ ), amphiregulin, heparinbinding EGF and $\beta$-cellulin] bind to the EGF receptor (EGF-R), which is a transmembrane glycoprotein localized to cell surfaces (Prigent and Lemoine, 1993). The predominant biological responses to ligand binding in the ovary are cell proliferation, differentiation and the modulation of hormone production (Gospodarowicz and Bialecki, 1979; Hsueh et al., 1981; Erickson and Case, 1983; Johnson et al., 1991). The EGF-R has been localized to the granulosa and theca cells of preovulatory follicles in several mammals (St Arnaud et al., 1983; Chabot et al., 1986; Balboni et al., 1988; Fujinnaga et al., 1992) and the corpus luteum (Ayyagari and Khan-Dawood, 1987; KhanDawood, 1987). TGF- $\alpha$ is also present in the ovaries of several species, in which expression is confined to the theca (Kudlow et al., 1987; Skinner et al., 1987; Lobb et al., 1988; Roy and Greenwald, 1990; Chegini and Williams, 1992). However, little is known about the occurrence of these growth factors or their receptors in the avian ovary. The avian EGF-R encoded by the $c-e r b B$ gene has, however, been cloned, and sequence analysis has shown that it is structurally similar to the human EGF-R of $170 \mathrm{kDa}$ (Lax et al., 1988b); the structure of the ligand for this avian receptor is still unknown. We reported previously that EGF or TGF- $\alpha$ may have a physiological role in the avian ovary, as these ligands have mitogenic effects on both the granulosa and theca cells and modulate steroid production by both cell types in culture (Onagbesan et al., 1994; Peddie et al., 1994). In this study we have used immunohistochemical methods to show that cells within avian follicles have EGF receptors and also contain potential EGF- and TGF- $\alpha$-like peptides. Thus, there is further evidence that the autocrine and paracrine control of follicular function in birds may be influenced by this growth factor system.

\section{Materials and Methods}

\section{Tissues}

Yellow (FI-F4; i.e. largest to fourth largest) and large white (LW) follicles (4-7 $\mathrm{mm}$ in diameter) were collected from laying ISA-Brown hens $25-30$ weeks old. Birds laying 5-6 eggs per sequence were used for experiments and birds were selected at the second egg stage of the sequence. Tissues were obtained 2-4 $\mathrm{h}$ before the expected ovulation time, embedded in OCT compound (Miles Inc., Elkhart, IN), snap-frozen in isopentane/ liquid nitrogen, and stored at $-70^{\circ} \mathrm{C}$ before sectioning for immunohistochemical staining. 


\section{Antibodies}

A polyclonal rabbit antibody (12E) raised against a short sequence (nucleotides 1059-1072) of the cytoplasmic domain of the human EGF-R (Gullick et al., 1985) was used in this study to detect EGF receptors. The chicken EGF receptor sequence is the same in $12 / 14$ positions and the two amino acid differences are conservative (Lax et al., 1988b). Its use in immunohistochemistry has been described by Gullick et al. (1991). This affinity-purified antibody was used at a concentration of $4 \mu \mathrm{g} \mathrm{ml}^{-1}$ for staining.

Staining for the EGF and TGF- $\alpha$ peptides was accomplished with specific rabbit polyclonal antibodies raised against recombinant human EGF (whole sequence) and TGF- $\alpha$ (whole sequence) peptides (Biogenesis, Bournemouth). These antibodies do not crossreact and are specific for the peptides to which they were raised. The antibodies were applied at a dilution of 1:100. Biotinylated goat anti-rabbit immunoglobulin $G$ (Sigma Chemical Co., Poole) was used as a secondary antibody, at a dilution of 1:200.

\section{Immunohistochemistry}

Frozen tissues were sectioned at $6-8 \mu \mathrm{m}$ on a cryostat at $-20^{\circ} \mathrm{C}$, and layered on to gelatin-coated slides. Tissues were thawed and permeabilized in 1\% Triton X-100 (Sigma Chemical Co.). Endogenous peroxidase was blocked with $1 \%$ hydrogen peroxide in methanol (Sigma Chemical Co.) and nonspecific binding was blocked with $10 \%$ goat serum and blocking avidin-biotin (20 $\mu \mathrm{g} \mathrm{ml}$; Vector Labs, Peterborough). Primary antibodies were incubated with tissue sections overnight at $4^{\circ} \mathrm{C}$ and then with the secondary antibody for $\mathrm{Ih}$ at $37^{\circ} \mathrm{C}$. Immunolocalization was visualized using the horseradish peroxide and diaminobenzidine substrate kits (Vector Labs). Sections were lightly counterstained in haematoxylin, followed by dehydration and mounting in DPX (BDH Laboratory Supplies, Poole). Control tissues for each antisenum were obtained by omitting the primary antibody and incubating the tissues in nonimmune serum overnight, or by preabsorbing the EGF-R antibody with the corresponding immunizing peptide (12E) at concentration 10 times greater than that of the primary antibody. For the potential ligands, blocking the EGF and TGF- $\alpha$ primary antibodies was achieved with recombinant human EGF or TGF- $\alpha$ (Bachem, Saffron Walden, Essex), respectively. Furthermore, potential crossblocking of the antibodies was performed with heterologous peptides to demonstrate the specificity of the antibodies. Human placental tissue, which is known to express the EGF-R, and human tonsil tissue, which expresses the ligands, were included in the experiments to validate the use of this technique in avian tissues.

\section{Results}

Figure 1 shows haematoxylin and eosin staining of a section through the $\mathrm{F} 3$ chicken ovarian follicle illustrating the granulosa $(G)$, theca interna (TI) and theca externa (TE) layers. Immunohistochemical localization of EGF receptors and the potential ligands in the different layers is demonstrated in Figs 2 and 3, respectively. Immunostaining with the different

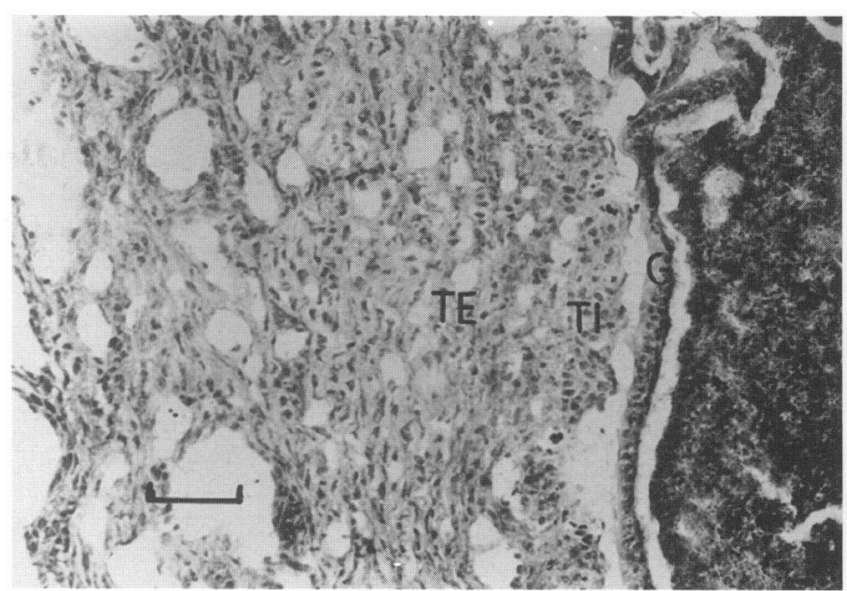

Fig. 1. Photomicrograph of the haematoxylin and eosin staining of a section of a chicken ovarian follicle showing the granulosa $(G)$, theca interna (TI) and the theca externa (TE) layers. Scale bar represents $7 \mu \mathrm{m}$.

antibodies was classified as negative $(-)$ or positive $(+:$ light; $++:$ moderate; $+++:$ intense) as represented in Tables 1,2 and 3. Some staining was obtained with each of the antibodies, with variations in the localization of EGF-R, EGF or TGF- $\alpha$. These effects were abolished by omitting the primary antibodies or by preincubating the antibodies with the corresponding immunizing peptides.

Immunolocalization of EGF-R was found in the granulosa, the theca interna and the theca externa. Staining was more intense in the theca interna than in either the externa or the granulosa layers with the $12 \mathrm{E}$ primary antibody (Fig. 2). In all follicles studied (F1-F4 and LW), medium-sized and small follicles tended to show comparatively more intense staining (F3 $<$ F4 $<\mathrm{LW}$ ) than did larger, more mature follicles $(\mathrm{F} 1<\mathrm{F} 2)$. The results of EGF-R staining are summarized (Table 1).

Immunostaining for the EGF- and TGF- $\alpha$-like peptides using polyclonal antibodies raised to recombinant human EGF or TGF- $\alpha$ were detected in both theca and granulosa layers. Staining for EGF was again more intense in the theca interna and granulosa layers, with moderate staining in the theca externa. TGF- $\alpha$ staining was, however, most intense in the theca externa, with moderate staining on the interna and granulosa layers (Fig. 3). Overall, immunostaining was often more intense to the EGF than to the TGF- $\alpha$ antibody. Differential expression of the peptides, as noted by the intensity of staining, was also observed in the hierarchy of follicles studied. The intensity of staining tended to decrease with increasing size of follicles (see Tables 2 and 3) and particularly in the theca externa between the F3 and F2 follicles.

Cellular localization shows that EGF-R was present on both the cell membrane and the cytoplasm. EGF seemed to be predominantly cytoplasmic,but TGF- $\alpha$ was localized mainly on cell membranes and also showed a perinuclear staining (Fig. 4).

\section{Discussion}

There is increasing evidence that growth factors have a role in the avian ovary. Our previous data (Onagbesan et al., 1994; 

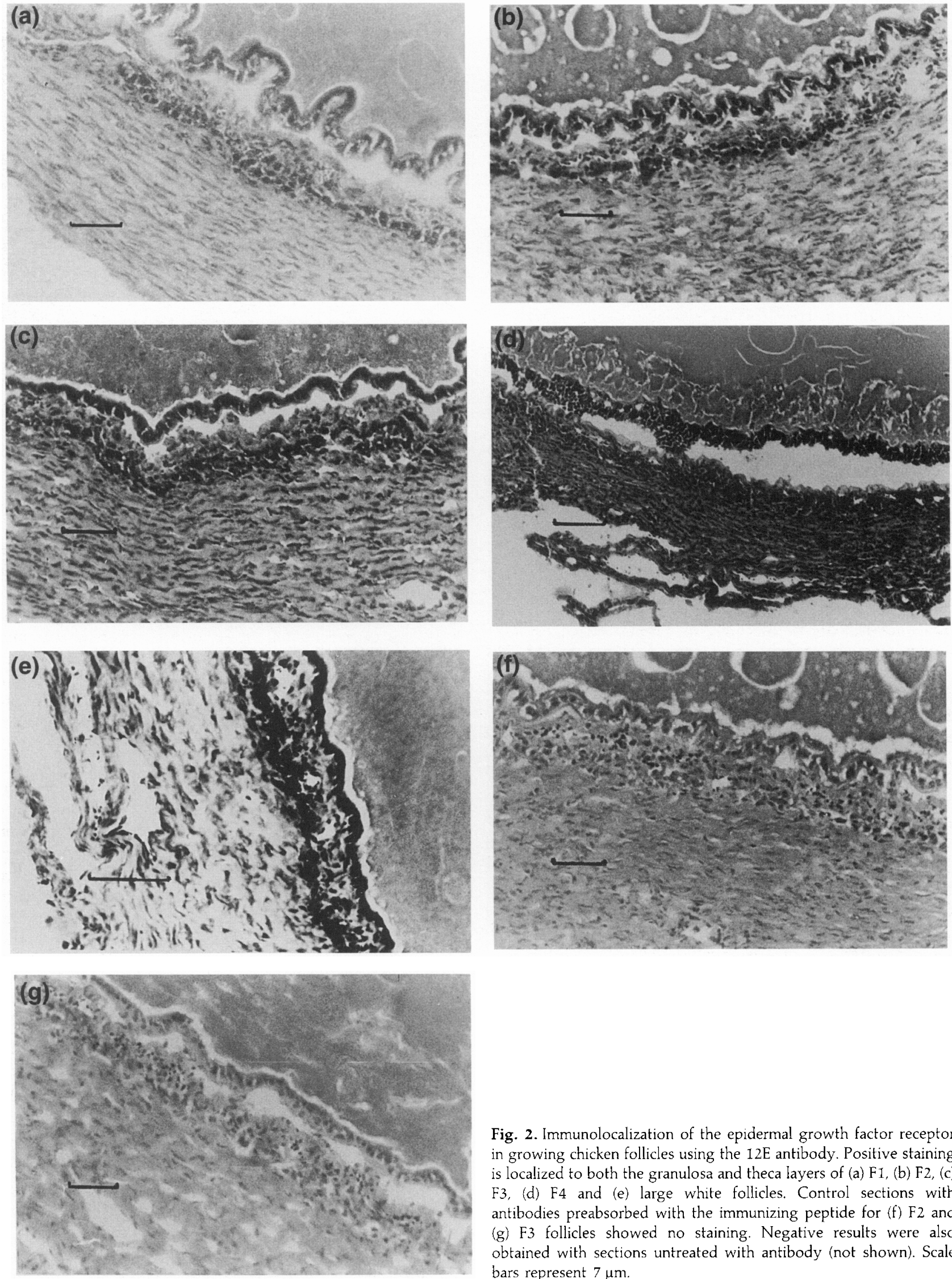

Fig. 2. Immunolocalization of the epidermal growth factor receptor in growing chicken follicles using the $12 \mathrm{E}$ antibody. Positive staining is localized to both the granulosa and theca layers of (a) F1, (b) F2, (c) F3, (d) F4 and (e) large white follicles. Control sections with antibodies preabsorbed with the immunizing peptide for (f) F2 and (g) F3 follicles showed no staining. Negative results were also obtained with sections untreated with antibody (not shown). Scale bars represent $7 \mu \mathrm{m}$. 


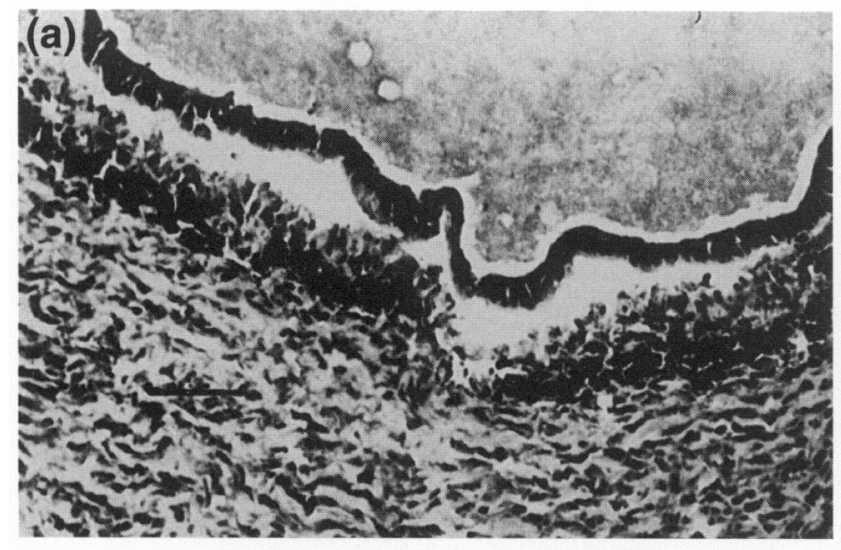

(c)

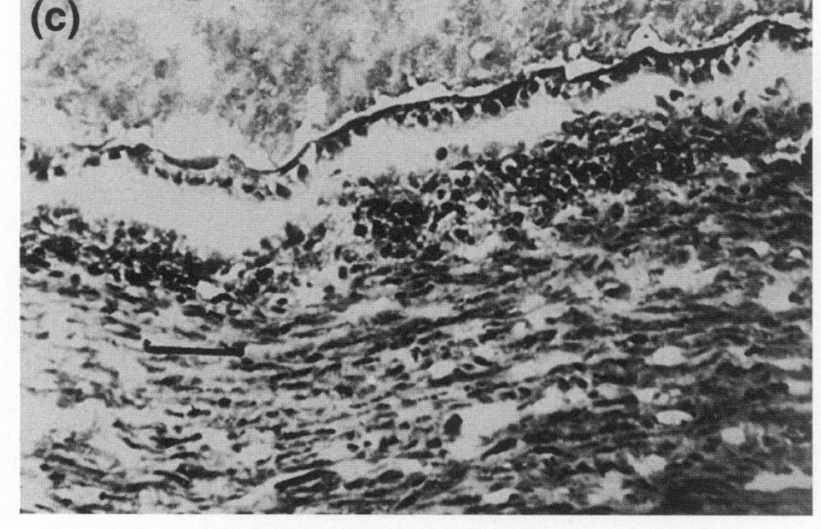

(e)

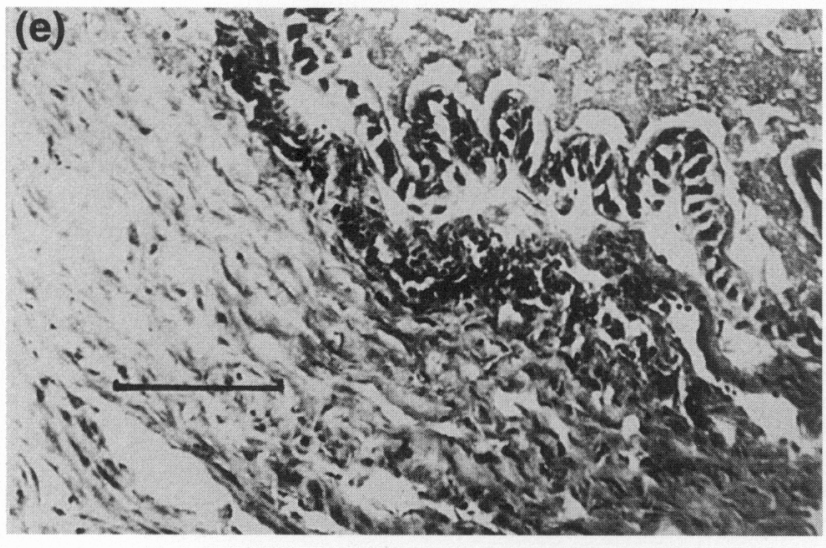

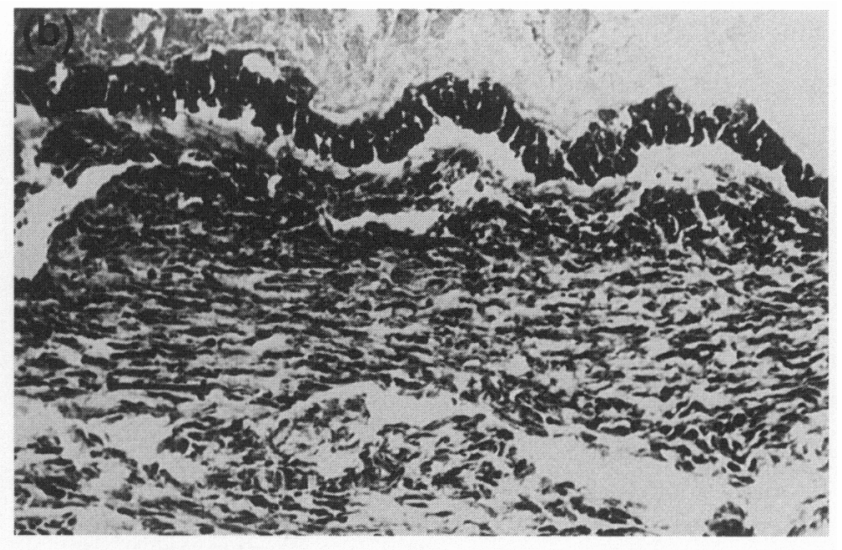
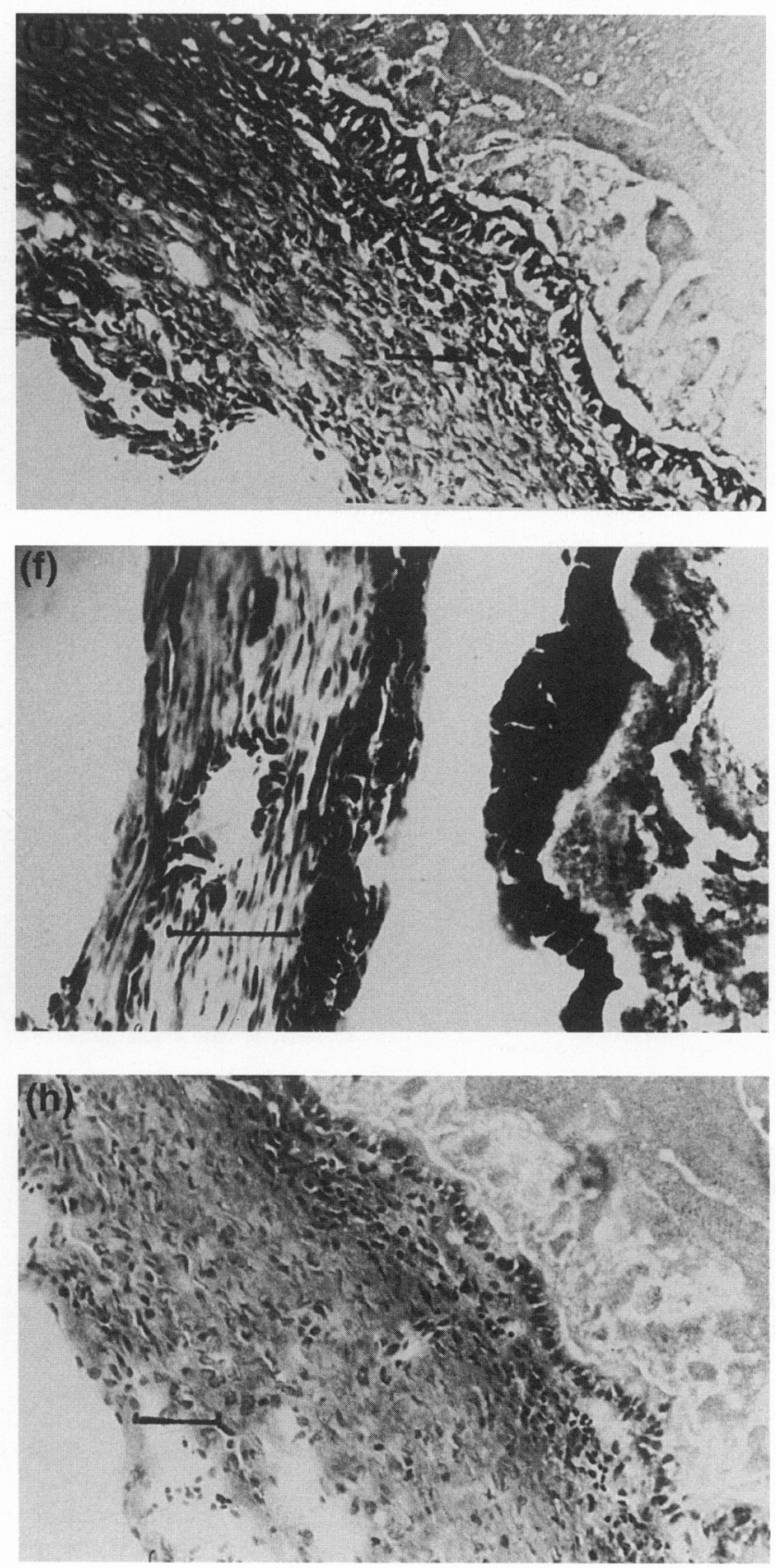
Table 1. Intensity of immunohistochemical staining for the epidermal growth factor receptor in the ovarian follicles of chicken

\begin{tabular}{lcccc}
\hline Antibody & Follicles & Granulosa & Theca interna & Theca externa \\
\hline 12E & F1 & ++ & ++ & + \\
& F2 & ++ & ++ & + \\
& F3 & +++ & +++ & + \\
& F4 & +++ & +++ & ++ \\
CW & F1-LW & +++ & +++ & + \\
Control 1 & F1-LW & - & - & - \\
\hline
\end{tabular}

Sections were stained with $12 \mathrm{E}$ antibody, and staining intensity is classified as light $(+)$, moderate $(++)$ or intense $(+++)$ for positive results, or negative $(-)$ for no staining.

Control 1: the control experiment without the addition of the primary antibody.

Control 2: the control experiment with the primary antibody preincubated with the immunizing peptide.

LW: large white.

Table 2. Intensity of immunohistochemical staining for epidermal-growth-factor-like peptide in the ovarian follicles of the chicken with a specific polyclonal antibody to recombinant human epidermal growth factor

\begin{tabular}{lcccccc}
\hline & F1 & F2 & F3 & F4 & LW \\
\hline Granulosa & + & + & +++ & +++ & +++ \\
Theca interna & + & ++ & +++ & +++ & +++ & ++ \\
Theca externa & + & + & ++ & ++ & ++ & \\
\hline
\end{tabular}

Staining intensity is classified as light $(+)$, moderate $(++)$ or intense $(+++)$ for positive results.

LW: large white.

Table 3. Intensity of immunohistochemical staining for transforming-growth-factor-like peptide in ovarian follicles of chicken with a specific polyclonal antibody to recombinant human transforming growth factor $\alpha$

\begin{tabular}{lccccc}
\hline & F1 & F2 & F3 & F4 & LW \\
\hline Granulosa & + & + & + & ++ & ++ \\
Theca interna & + & + & + & ++ & ++ \\
Theca externa & + & + & ++ & ++ & ++ \\
\hline
\end{tabular}

Staining intensity is classified as light $(+)$, moderate $(++)$ or intense $(+++)$ for positive results.

LW: large white.

Peddie ef al., 1994) showed that EGF or TGF- $\alpha$ stimulated cell proliferation and inhibited steroid production in the granulosa and theca cells of the chicken ovary. This study has demonstrated the presence of receptors for these ligands in chicken follicles and the possible presence of ligands as well. The variation in the distribution of staining indicated a greater concentration of receptors in the theca interna layer using an antibody directed against the internal domain of the receptor. Similarly, both the granulosa and the theca were sites of EGFand TGF- $\alpha$-like peptides, as indicated by the intensity of staining. Furthermore, the results show a distinct variation in the distribution pattern of both EGF-R and EGF- and

Fig. 3. Immunostaining for peptides like epidermal growth factor (EGF) and transforming growth factor $\alpha$ (TGF- $\alpha$ ) in the maturing ovarian follicles of the chicken using specific polyclonal antibodies to recombinant EGF and TGF- $\alpha$. The photomicrographs show positive staining for EGF in the granulosa and theca layers of (a) the F3 and (b) F4 follicles, and positive staining for TGF- $a$ also in all layers of (c) the F3 and (d) F4 follicles. (e, f) Positive staining of large white follicles for TGF- $\alpha$ and EGF, respectively. (g, h) Negative controls for F3 and F4, respectively. (a, b, $c$, d, g, h) Scale bars represent $7 \mu \mathrm{m}$; (e, $\mathrm{t})$ scale bars represent $14 \mu \mathrm{m}$. 

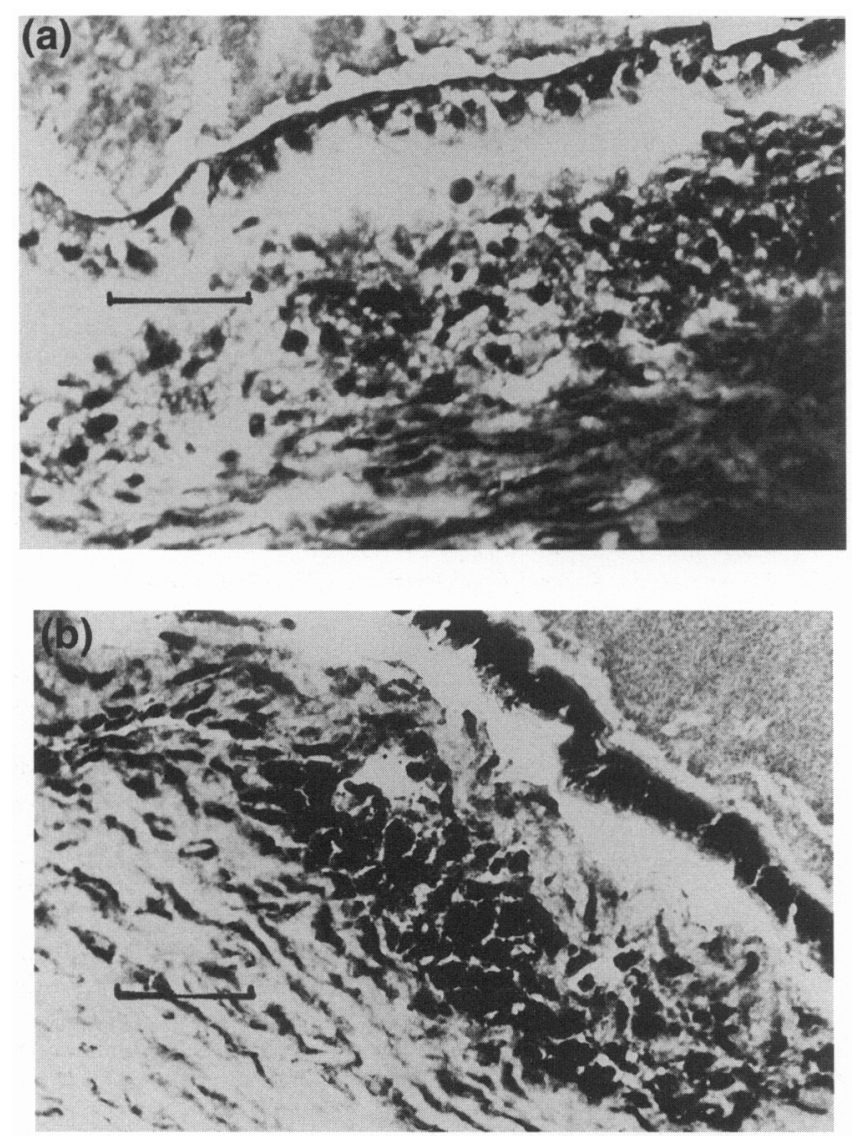

Fig. 4. Demonstration of the expression of transforming growth factor $\alpha$ (TGF- $\alpha$ ) and epidermal growth factor (EGF) in the F3 follicular tissues of the chicken ovary. (a) TGF- $\alpha$ staining in plasma membranes and perinuclear areas of the granulosa and theca. (b) Expression of EGF occurs predominantly in the cytoplasm of the granulosa and theca. Scale bars represent $24 \mu \mathrm{m}$.

TGF- $\alpha$-like peptides within the follicular hierarchy. These findings provide further evidence for a significant role for EGF and TGF- $\alpha$ and their receptors in the avian ovary.

Previously, we have reported that human EGF or human TGF- $\alpha$ can stimulate granulosa or theca cell proliferation in vitro, with greater effects on the cells from the smaller follicles (Onagbesan et al., 1994; Peddie et al., 1994). The localization of receptors for these ligands in both tissues correlate with those reported effects. Furthermore, the various effects of EGF and TGF $\alpha$ on granulosa and theca proliferation may be attributed partly to the differences in receptor expression; that is, the greater effect of EGF and TGF- $\alpha$ on the proliferation of small theca cells from LW follicles compared with F1 and F2 follicles could be due partly to the greater concentration of EGF-R expressed in these smaller follicles. Additional factors also contribute to the changing sensitivity of tissues to the ligands; for example, changes in receptor activation caused by ${ }^{125}$ I-labelled TGF- $\alpha$ binding to cultured granulosa or theca cells have confirmed the general trends in receptor distribution observed in the present immunohistochemical study (Woolveridge et al., 1993). The expression of EGF-R is a consistent feature in most mammalian ovaries
(St Amaud et al., 1983; Chabot et al., 1986; Balboni et al., 1988; Fujinaga et al., 1992). As is often the case, the receptors in the present study were found both on cell membranes and within the cytoplasm in the supranuclear regions, presumably reflecting internalized receptors.

The results indicate that EGF-like and TGF- $\alpha$-like peptides are located in both granulosa and theca layers of the small and large follicles; EGF was predominantly cytosolic and TGF- $\alpha$ bound to the surface membrane and perinuclear. This finding suggests that both growth factors and the EGF-R are expressed simultaneously in individual cells, since the two antibodies used in detecting the peptides did not crossreact and crossblocking with heterologous peptides was ineffective. Again, the intensity of staining reveals that the amount of peptides present varies between the different cell compartments and between follicles. Generally, staining is more widespread in the theca tissue than in the granulosa for all follicles, and declines as the follicle emerges from the rapid growth phase into the maturing and subsequently ovulatory phase. Different sites of EGF and TGF- $\alpha$ localization have been reported in mammals: theca in the bovine ovary (Lobb et al., 1989); but both granulosa and theca in rat and human ovaries (Chegini and Williams, 1992; Yeh et al., 1993). The results from this study correlate with the findings of others that the peptide concentrations are greatest in follicles undergoing the most rapid growth, with a decrease in concentration as the follicle approaches ovulation (Lobb et al., 1989).

The localization of the two peptides in two distinct parts of the cell is intriguing. Whether these represent local synthesis is unclear. The presence of TGF- $\alpha$ immunoreactivity on membranes may result from cleavage of TGF- $\alpha$ from transmembrane proTGF- $\alpha$ and sequestration by binding to EGF-R, or it may indicate the involvement of TGF- $\alpha$ in cell-cell communication. The precise source of the EGF peptide detected in the cytoplasm is unclear. The localization of EGF-like and TGF- $\alpha$ like peptides as an indication of site of production cannot immediately be reconciled with some of our data (Peddie et al., 1994), which indicated that the theca was the major source of secreted peptide. We found that whereas theca-conditioned medium stimulated cell proliferation and inhibited steroidogenesis in cultured theca and granulosa cells, granulosaconditioned medium had no effect. Similarly, theca conditioned medium displaced ${ }^{125}$ I-labelled EGF or ${ }^{125}$ I-labelled TGF- $\alpha$ from human placental membranes while granulosa-conditioned medium did not (Woolveridge et al., 1993). As for the nature of peptide secreted, protein analysis of tissue extracts and conditioned media using western analysis demonstrated that TGF- $\alpha$ may be the likely peptide, since we could not detect EGF (I. Woolveridge, O. M. Onagbesan and M. J. Peddie, unpublished). Although the antibody used to stain for EGF is specific for the peptide, detection of other proteins that contain EGF-like domains in the tissue cannot be excluded; alternatively, the visualized peptide may represent internalized ligand-receptor complexes. Further studies on EGF and TGF- $\alpha$ mRNA in the avian ovary would provide more detailed information, but as yet the sequence of these peptides or genes in avian tissues has not been reported.

In summary, this study demonstrates the presence of immunoreactive EGF-R, EGF and TGF- $\alpha$ in the granulosa and theca layers of the chicken ovarian follicles. EGF-R was 
detected in the plasma membranes as well as in the cytosol. EGF was located in the cytoplasm but TGF- $\alpha$ in the plasma membrane and perinuclear areas. The immunostaining pattern of the localization of both EGF-R and the ligands vary with the cell type and decrease as the follicles mature. The data suggest that EGF-R and the ligands may be potential regulators of avian ovarian function.

This sfudy was supported by the Joumals of Reproduction and Fertility Ltd and AFRC.

\section{References}

Ayyagari RR and Khan-Dawood FD (1987) Human corpus luteum: presence of EGF receptors and binding characteristics American Joumal of Obstetrics and Gynaecology 156 942-946

Balboni GC, Barni T, Vanneli GB and Serio M (1988) EGF and its receptors in human ovarian follicles: an immunohistochemical study Archives of Italian Anatomy and Embryology 93 205-215

Chabot JG, St Arnaud R, Walker P and Pelletier G (1986) Distribution of EGF receptors in rat ovary Molecular and Cellular Endocrinology 44 99-108

Chegini N and Williams RS (1992) Immunocytochemical localization of transforming growth factors (TGFs) TGF $\alpha$ and TGF $\beta$ in human ovarian tissues Journal of Clinical Endocrinology and Metabolism 74 973-980

Erickson GF and Case E (1983) Epidermal growth factor antagonizes ovarian theca-interstitial cytodifferentiation Molecular and Cellular Endocrinology 31 $71-76$

Fujinaga H, Yamoto M, Nakano R and Shima K (1992) EGF binding sites in porcine granulosa cells and their regulation by FSH Biology of Reproduction $46705-709$

Gospodarowicz D and Bialecki H (1979) Fibroblast and epidermal growth factors are mitogenic agents for cultured granulosa cells of rodent, porcine and human origin Endocrinology 104 757-764

Gullick WJ, Downward J and Waterfield MD (1985) Antibodies to the autophosphorylation sites of the EGF receptor protein-tyrosine kinase as probes of structure and function EMBO Journal 4 2869-2877

Gullick WJ, Hughes CM, Mellon K, Neal DE and Lemoine NR (1991) Immunohistochemical detection of the epidermal growth factor receptor in paraffinembedded human tissues Joumal of Pathology 164 285-289

Hsueh AJW, Welsh TH and Jones PBC (1981) Inhibition of ovarian and testicular steroidogenesis by epidermal growth factor Endocrinology 108 2002-2004
Johnson GR, Saeki T, Auersperg N, Gordon AW, Shoyab M, Salomon DS and Stromberg K (1991) Response to and expression of amphiregulin by ovarian carcinoma and normal ovarian surface epithelial cells: nuclear localization of endogenous amphiregulin Biochemical and Biophysical Research Communications $180481-488$

Khan-Dawood FS (1987) Human corpus luteum: immunocytochemical localization of epidermal growth factor Fertility and Sterility 47 916-919

Kudlow JW, Kobrin MS, Purchio AF, Twardzik DR, Hernandez ER, Asa SL and Adashi EY (1987) Ovarian TGFa gene expression: immunohistochemical localization to the theca-interstitial cells Endocrinology 121 1577-1579

Lax I, Johnson A, Howk R, Sap J, Bellot F, Winkler M, Ullrich A, Vennstrom B, Schlessinger J and Givol D (1988b) Chicken epidermal growth factor (EGF) receptor: $\mathrm{CDNA}$ cloning, expression in mouse cells, and differential binding of EGF and transforming growth factor alpha Molecular and Cellular Biology 8 1970-1978

Lobb DK, Skinner MK and Dorrington JH (1988) Rat theca-interstitial cells produce a mitogenic activity that promotes the growth of granulosa cells Molecular and Cellular Endocrinology 55 209-217

Lobb DK, Kobrin MS, Kudlow JE and Dorrington JH (1989) TGF $\alpha$ in the adult bovine ovary: identification in growing follicles Biology of Reproduction $\mathbf{4 0}$ 1087-1093

Peddie MJ, Onagbesan OM and Williams J (1994) Chicken granulosa cell proliferation and progesterone production in culture: effects of EGF and theca secretions General and Comparative Endocrinology 94 341-356

Prigent SA and Lemoine NR (1993) The type 1 (EGFR-related) family of growth factor receptors and their ligands Progress in Growth Factor Research 4 1-24

Onagbesan OM, Peddie MJ and Williams J (1994) Regulation of cell proliferation and estrogen synthesis by LH, IGF-I and EGF in theca cells of the domestic hen cultured in defined media General and Comparative Endocrinology 94 261-272

Roy SK and Greenwald GS (1990) Immunohistochemical localization of epidermal growth factor in the hamster ovary with a polyclonal antibody Endocrinology 126 1309-1317

St Arnaud R, Walker P, Kelly PA and Labrie F (1983) Rat ovarian epidermal growth factor receptors: characterization and hormonal regulation Molecular and Cellular Endocrinology 31 43-52

Skinner MK, Lobb D and Dorrington JH (1987) Ovarian theca-interstitial cells produce an EGF-like substance Endocrinology 121 1892-1899

Woolveridge I, Onagbesan OM and Peddie MJ (1993) Alterations in the ${ }^{125}$ I-TGF $\alpha$ binding to granulosa and theca cells during follicular maturation in chickens Journal of Reproduction and Fertility Abstract Series 12 Abstract 58

Yeh J, Lee GY and Anderson E (1993) Presence of TGF $\alpha$ mRNA and absence of EGF mRNA in rat ovarian granulosa cells and the effects of these factors on steroidogenesis in vitro Biology of Reproduction 48 1071-1081 